\title{
Impact of Noise Exposure on the Reliability of the Human Factor in the Production Hall
}

\author{
Marta Vargová, Lukáš Salaj, Daniel Jurč, Katarína Chomová, Michaela Balážiková* \\ Technical university of Košice, Faculty of Mechanical Engineering, Department of Safety and Quality Production, Letná 9, 04013 Košice, Slovakia
}

\begin{abstract}
The subject of the paper is the analysis of the impact of noise exposure of human reliability in a production workplace with a high noise load. Long-term monitoring of the effects of low frequencies on human hearing has been shown to be the risk of harm to human health caused by this effect. The negative effects of noise on human health manifest themselves primarily in the areas of the human auditory organ, permanent and incurable disorders. The paper proposes a method to assess the reliability of the human factor in noise exposure operations. Practical measurement of noise exposure was carried out in heavy machinery operation, welding workplace. The risk assessment was carried out using the TESEO method. Based on the assessment, possible human errors in the operation were identified.
\end{abstract}

Keywords: Noise, Reliability, Welding

\section{Introduction}

In terms of risk, noise is the most common harmful factor in the work environment in Slovakia. Noise can cause or trigger several diseases such as anxiety, cardiovascular disease, depression, stroke, and, long-term exposure to noise above $85 \mathrm{~dB}$ may cause permanent hearing loss. Noise is any unwanted, annoying, disturbing or harmful sound. It spreads through the sound waves that transmit acoustic energy. Continuous improvement is part of workplace safety management. Improvement itself is not only about ensuring a suitable and safe working environment, but also about the impact on employees' health. Each company aims to ensure conditions for its employees so that the risks they face are minimized or eliminated.

The actual measurement of noise in individual work positions in the work environment is carried out to assess the exposure to noise to the health of the employee and other people occurring in the work environment. This is a risk assessment to protect employees' health.

The noise determining quantity (i.e., the quantity that quantitatively characterizes noise and is used to assess noise exposure in terms of health and safety at work) is the normalized noise exposure level. It is a time-weighted value (i.e., it is recalculated for a certain period) and represents the employee's exposure for an 8-hour shift and a 40-hour week. At present, in accordance with the European Directive, the concepts of quantities determining noise exposures shown in Tab. 1 were introduced into the Slovak legislation (Annex No. 2 of the Order of the Government of the Slovak Republic No. 115/2006 Coll. as amended by the Order of the Government of the Slovak Republic No. 555/2006 Coll.) [3]

In carrying out a work activity, the "Exposure Action Value" is the value at which, if exceeded, measures must be taken, whether technical, organizational or otherwise, to reduce working noise to an acceptable level (measures under Section 4, par (1) of the order of the Government of the Slovak Republic No. 115/2006 Coll. that bring

* Corresponding author: Michaela Balážiková, E-mail address: michaela.balazikova@tuke.sk 
Table 1: Noise exposure action and limit values [1].

\begin{tabular}{|l|l|l|}
\hline Exposure limit value & $\mathrm{L}_{\mathrm{AEX}, 8 \mathrm{~h}}=87 \mathrm{~dB}$ & $\mathrm{~L}_{\mathrm{CPK}}=140 \mathrm{~dB}$ \\
\hline Exposure upper action value & $\mathrm{L}_{\mathrm{AEX}, 8 \mathrm{~h}}=85 \mathrm{~dB}$ & $\mathrm{~L}_{\mathrm{CPK}}=137 \mathrm{~dB}$ \\
\hline Exposure lower action value & $\mathrm{L}_{\mathrm{AEX}, 8 \mathrm{~h}}=80 \mathrm{~dB}$ & $\mathrm{~L}_{\mathrm{CPK}}=135 \mathrm{~dB}$ \\
\hline
\end{tabular}

the expected effect and actually contribute to the protection of employees' health).

Human reliability analysis allows us to detect human errors or the effects of these errors. This analysis shows us a systematic assessment of the factors that are influenced by the activities of workers, technicians, and a wide range of employees who work in the working environment and in the production itself. Assessment factors point to errors that are in a critical state and factors contributing to critical errors but also point to possible modifications to the systems that can be designed to reduce the likelihood of errors. By means of analysis, it is possible to identify places that are affected by various errors or by order of these errors and at the same time to combine them in classical operation by technologies, based on the statistical probability of the occurrence of accidents and the severity of their impacts. The results themselves can be updated after every change of the production process or project.

\section{Experimental Material and Methods}

\subsection{Place of Measurement}

The object of measurement of noise exposure, in order to assess human reliability as a quantitative parameter, is heavy machinery operation, which is specified to produce steel portals, their bogies and to produce specific water barriers. To determine the real noise load, it is necessary to point out that the entire production process consists of various activities such as machine bevelling, heating and straightening with acetylene flame, impurities grinding and material corrosion, welding of subgroups and resulting portions of portals, carbon electrode gouging, and robotic welding.

In the place of measurement, i.e. in the company, 180 employees work, of which 6 are women in administration and 90 employees, which occur or move there daily and thus they spend their working time in operation. The main working activities that are performed in the working environment are the activities of tooler, grinder, welder, locksmith, and welding robot operator. [1]
Two shift 8-hour working time is introduced in the workplace.

Based on this parameter, we know that the daily normalized A noise exposure level is LAeq, 8h, which is determined from the 8-hour working time. The company is predominantly equipped with welding equipment with which the employee works in his / her place during his / her work change. Workers are equipped with a worktable, a straight and angle grinder, a bridge and traveling cantilever crane, magnets and load-carrying hooks, heating and cutting hand torch, a power source with a welding wire feeder, a hand toolbox with hand tools and measuring tools. [2]

When ensuring safety at the workplace, the employer is subject to general obligations arising from Act No. 124/2006 Coll. on health and safety at work. The employer is also given specific obligations, which are regulated by Act No. 355/2007 Coll. on protection, promotion, and development of Public Health and Order of the Government of the Slovak Republic No. 115/2006 Coll. on the minimum health and safety requirements for the protection of health against the risks related to exposure to noise. [4]

In terms of noise, the employer is obliged:

- to carry out a risk assessment of exposure to noise,

- to implement measures to eliminate or reduce the risk of noise to an acceptable level,

- to provide practical training and information for employees,

- to provide health surveillance for employees.

Noise exposure is defined as noise generated using mechanical technology equipment, but also noise generated by the environment during working hours. $[5,8]$

\subsection{Used Measuring Instruments}

A specialized instrument - Bruel \& Kjaer Type 2250 Hand Sound Analyzer - was used to measure the noise exposure in the selected company and to evaluate it. Types 2250 is flexible hand-held analyzer that cover all sound and vibration measurement and analysis needs - from the traditional uses in assessing environmental and workplace noise to industrial quality control and development. The high-resolution touchscreen allows to easily navigate through the setup menu tailoring one of the many predefined templates to precisely your measurement requirements. [7]

The large dynamic range copes with both the loudest noises and those just above the noise floor and the frequency range, extended with the 
low-frequency option, spans from $20 \mathrm{kHz}$ down to infrasound for measurement of noise sources suspected of emitting very low frequency noise. In Fig 1, the process of measurement in the production hall is shown. The hand-held analyzer is used to measure broadband exposure measurements of various types of noise. It can be measured in internal as well as external environment. It is a durable and easy-to-use Class 1 sound level meter, ideal for immediate noise measurements but also for occupational safety and health assessments. The device meets the requirements of IEC 61672-1.

During measurement, the use of a sound analyzer allows real-time audio analysis to be measured in the 1/1-octave bands (centre frequency from $8 \mathrm{~Hz}$ to 16 $\mathrm{kHz}$ ) and 1/3-octave (centre frequencies from $6.3 \mathrm{~Hz}$ to $20 \mathrm{kHz}$ ). The modular and optimized software BZ5503 was also used to process the measured values. [6]

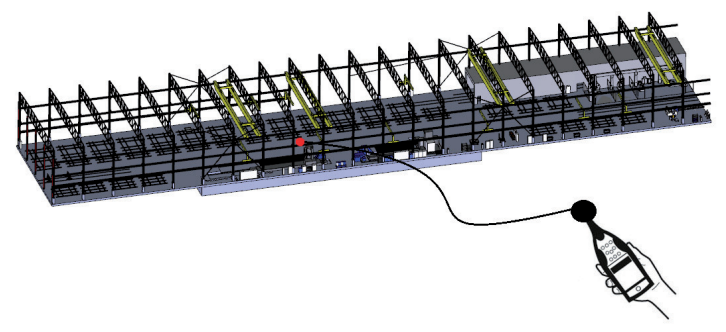

Figure 1:Visual 3D Model of the Hall with Demonstration of the Measuring Instrument.

\subsection{Conditions and Measurement Procedure for Work}

For the given noise study, noise exposure measurements were performed at three workplaces where work activities were performed by the company's specialized personnel. When assessing the acoustic situation, it is necessary to consider the microclimatic conditions at the workplace, i.e.:

- atmospheric pressure: $1016 \mathrm{hPa}$

- air temperature: $18^{\circ} \mathrm{C}$

- relative humidity: $60 \%$

First, it should be noted that the noise measurement was carried out in accordance with STN EN ISO 9612: 2009. Noise measurement requires a strategic plan that depends on many factors to be determined based on work activity and location of measurement. For the purpose of identifying workplace exposure to noise by a worker or a group of workers, the strategy outlines three key strategy points:
- job duties/performance measurement,

- type of work/task performed measurement,

- all-day measurement.

The choice of measurement itself depends on the complexity of the work, its procedures, the type of measurement, the number of employees who spend their time at the workplace, the duration of the job at the place of work, but also the type of tools used. During the measurement, the measurement interval must be long enough to be sufficiently demonstrable for an adequate equivalent sound pressure level. For work carried out by employees, the strategy of measuring the work duties or performance where the measured parameters were LAeq, where $A$ is the weighted equivalent continuous sound pressure level.

\subsection{Measurement Process at Measuring Points}

During a working activity such as welding, noise can sometimes be as high as $130 \mathrm{~dB}$, while welding at the workplace itself is not the only source of noise to which a worker or group of workers is exposed. The resulting sound perception that we perceive is influenced by various factors that are still under investigation. One of the most important factors is the different sensitivity of human hearing to different frequencies that we perceive as sound. Fig. 2 shows frequencies to better understand the sensitivity of the human ear. [3]

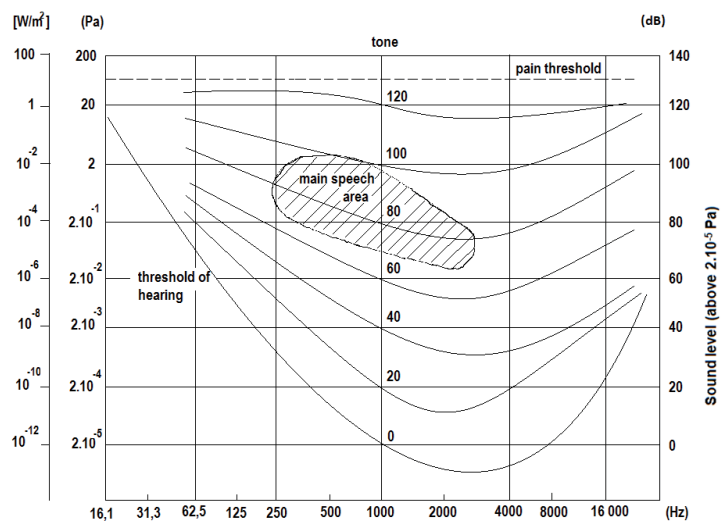

Figure 2: Sensitivity of the Human Ear.

The Bruel \& Kjaer Type 2250 noise analyzer was used at the workplaces to measure noise exposure, mounted on a stable tripod, equipped with flexible sides to isolate sound from possible vibrations that can cause poor measurements. The measurement was performed with a weight filter A (approximation 
of the same loudness curves for the low sound pressure range). The height of the mounted noise analyzer was at the level of the worker at a ground level approximately 1.5 meters above the ground. The measured results were stored in the memory of the noise analyzer and then transferred and processed using the computer software BZ-5503. The measurement of each activity was carried out at 15-minute intervals. To avoid distortion of the measured noise level, it was necessary to provide a firm and solid surface from the body to the noise analyzer. For uniform results of a series of measurements, it was necessary to observe a distance of at least:

- 1 meter from walls or other main reflecting surfaces that could distort unmeasured values,

- 1.3 to $1.5 \mathrm{~m}$ above the floor of the workplace,

- 1 meter from the windows if they are in the working environment.

At high frequencies, all disturbing and otherwise disturbed objects may degrade the microphone frequency response and thus the sound routing effect. The standard deviation of 1.0-1.5 dB and the measurement uncertainty of 2.2-2.6 dB in the measurement results should be considered.

\subsection{Description, Adjustment, and Marking of Measuring Points}

The actual process of production by the welder starts with a visual inspection of the preparation of welded joints, eventually by de-dusting with compressed air, followed by welding itself. The place of measurement is the place of operation in the production hall of the company with dimensions of $200 \mathrm{~m} \times 25 \mathrm{~m}$. There are no windows in the space, only roof skylights, which illuminate the space with the help of LED lighting. The ceiling of the production hall is 15 meters high.

In Fig. 3, there is a plan view of the workspace in which noise exposure during work is measured. Also, in Fig. 4, there is a 3D view of the workspace.

The robotic welding workplace works by the production operator, who controls the welding process and eventually corrects its movement. Two operators work in the workplace and they change after 8 hours of work.

The second measuring point was at the workplace where classical manual welding is carried out by the workers, Fig. 5. At this workplace, there is a workbench with a welding machine. As at the previous workplace, during welding, the noise concentration is also high, with the difference of the worker's concentration for the activity. The worker's

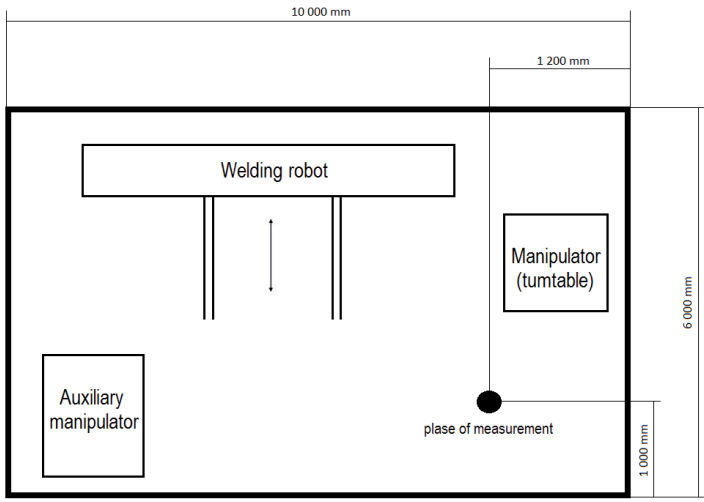

Figure 3: Robotic Welding Workplace Plan.

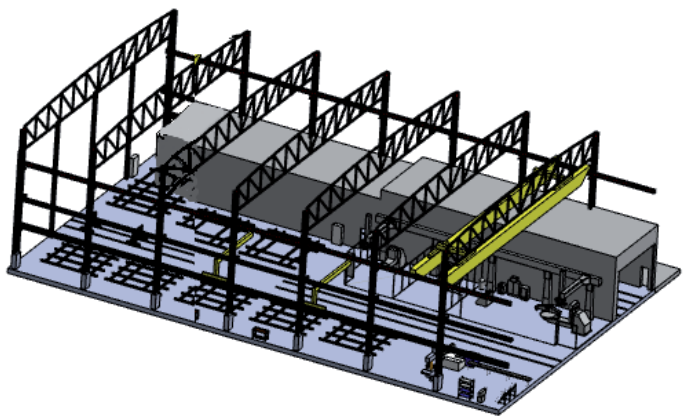

Figure 4: 3D Model of Workplace for Robotic Welding.

job description consists of welding itself using smaller tools, the quality of the welds is checked, and appropriate working procedures are followed. The manual welding workplace is shown in the 3D models in Fig. 6.

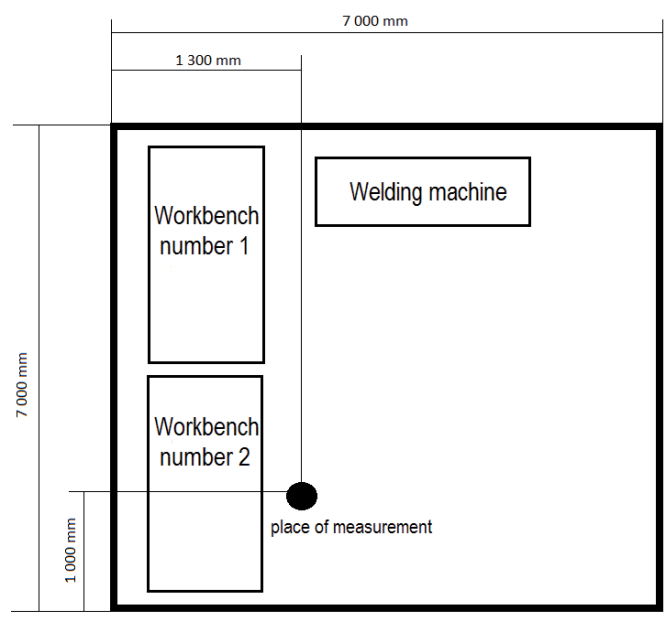

Figure 5: Manual Welding Workplace Plan. 


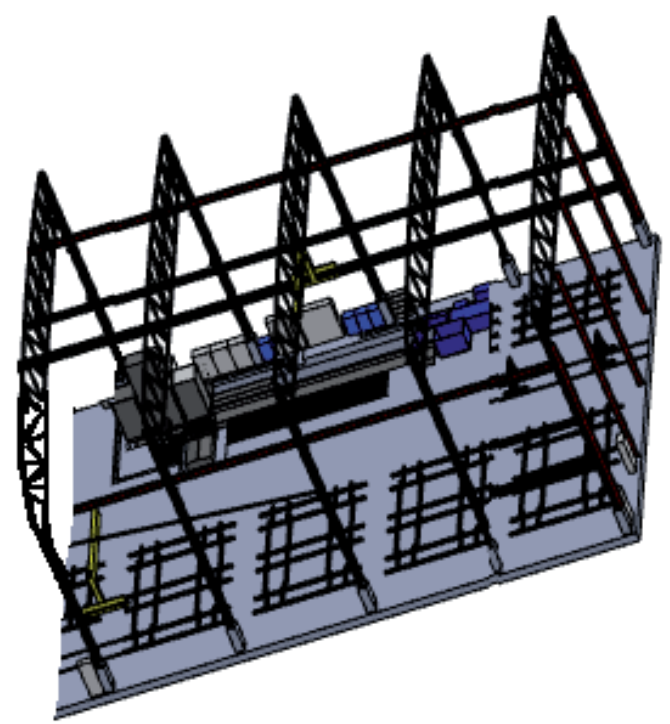

Figure 6: 3D Model of the Workplace for Manual Welding.

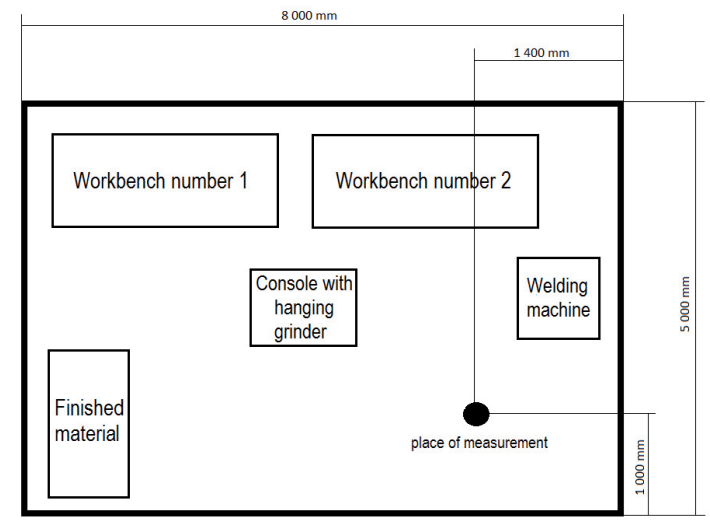

Figure 7: Grinding Workplace Place.

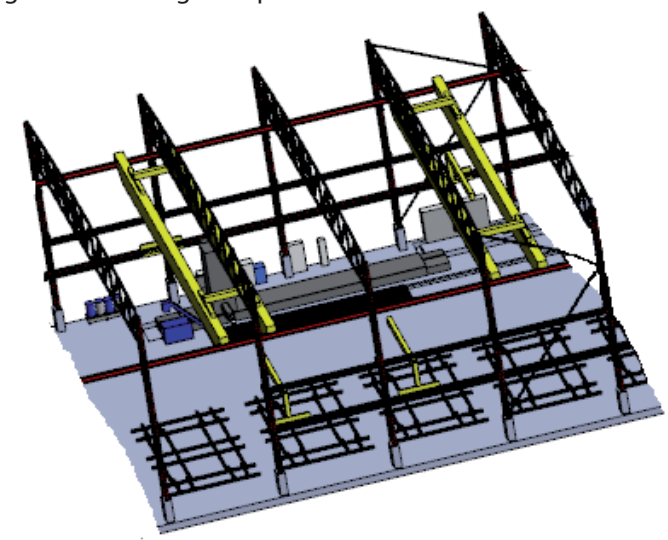

Figure 8: 3D Model of Workplace for Grinding.

The third measuring point is a workplace designed for grinding of finished welds or corrosion on materials, Fig. 7 and Fig. 8 3D workplace model.
The grinding process is somewhat noisier than manual welding, but it does not reach as much noise as robotic welding. Work activity consists of adjusting grinding machines and equipment, machining products using grinding machines and performing simple surface treatments of semifinished products.

Individual measurements at three workplaces were carried out with a weight filter A, which is intended for the area of low sound pressure levels. The measured values are shown in the following Tab. 2. The measured values were recorded during the worker's work and are referred to as the $\mathrm{L}_{\text {Aeq }}$ level. Table 2: Measured LAeq levels in the production hall.

\begin{tabular}{|l|l|}
\hline Work activities & $\mathrm{L}_{\text {Aeq }}(\mathrm{dB})$ \\
\hline Attendance of welding robot & 89,3 \\
\hline Hand welding & 79,3 \\
\hline Hand grinding & 87,8 \\
\hline
\end{tabular}

The measured frequency weighting of noise is shown in the following figures, for the given workplace. Fig. 9 shows frequency weighing for workplace 1 - robotic welding; in Fig. 10 for workplace 2 - manual welding and Fig. 11 for workplace 3 - hand grinding.

\section{Method TESEO}

The reliability of the human factor is defined as the probability that a person performs work activity during the working hours for which he/she has been trained. The TESEO method was used to take account of ergonomic conditions in the workplace, namely the quantitative equation. Tecnica Empirica Stima Errori Operatori (TESEO method) is a method of human reliability assessment (HRA) that evaluates the probability of human error occurring during the completion of a specific task. From these analyzes, measures can then be taken to reduce the likelihood of errors in the system and thus lead to an improvement in the overall level of safety. The authors of this method are G. C. Bell and C. Columbori, who designed it in 1980 to estimate operator errors. It is a method of expert qualitative assessment of human failure. This method is one of the screening methods and is very specific and different from other methods of human factor reliability analysis. [3]

The method estimates the reliability of the human factor using five key factors, which were 


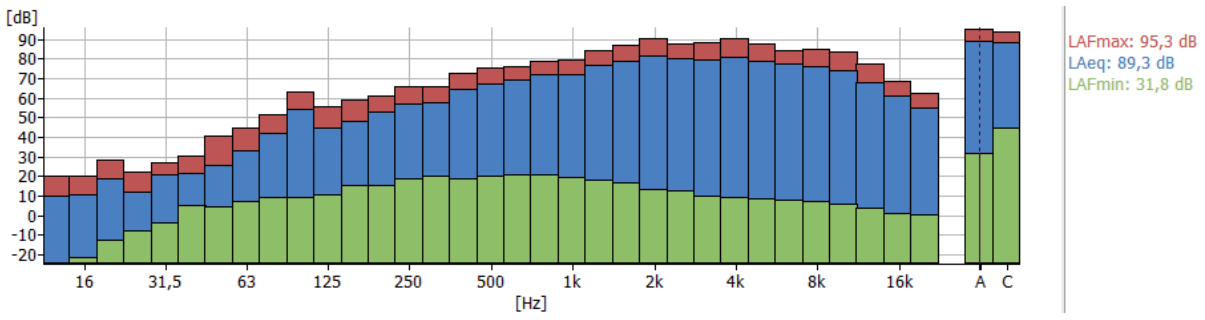

Figure 9: Frequency Noise Weighing for Workplace 1 - Robotic Welding.

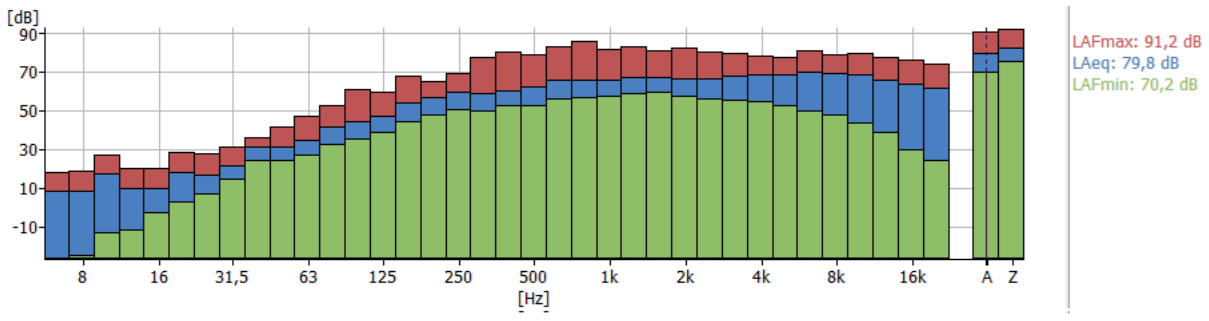

Figure 10: Frequency Noise Weighing for Workplace 2 - Manual Welding.

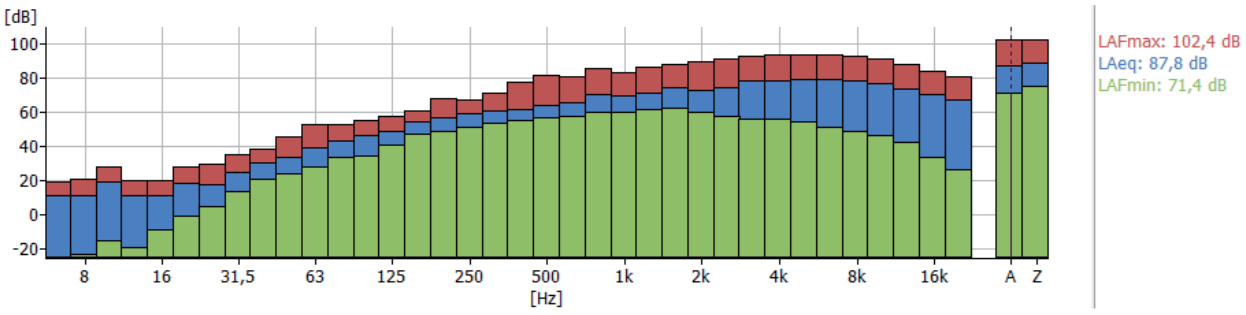

Figure 11: Frequency Noise Weighing for Workplace 3 - Manual Sanding.

assessed as the most important among all the factors influencing the probability of human error. Its model (G.C.Bello and C.Columbori, 1980) defines the probability of staff error as a multiplicative function of the following factors: - type of activity undertaken:

- (K1) = activity type factor - time available to perform the activity,

- (K2) = stress factor of normal activities, resp. stress factor of extraordinary activities - characteristics of workers,

- (K3) = operator quality factor - psychological state of workers,

- (K4) = anxiety and stress factor - local working conditions,

$-(K 5)=$ ergonomic factor.

As the aim of the article is to point out the impact of the quantitative parameter of occupational noise exposure on the reliability of the human factor, this method is the most accessible of all that assesses human reliability. The noise exposure parameter was incorporated into the K5 factor - an ergonomic factor.

This parameter is also based on legislative requirements. The TESEO method "Technica Empirica Stima Errori" was designed for the field of human reliability. The method evaluates the likelihood of human error and, based on this analysis, measures can be taken to reduce the likelihood of human error, to improve the overall level of safety in the workplace. This model is based on time describing the probability of human failure as a multiplicative function of the 5 major factors designated $\mathrm{K} 1$ to $\mathrm{K} 5$, as shown in Tab. 3. [3]

Table 3: 5 main factors for the TESEO method.

\begin{tabular}{|l|l|}
\hline Factor & Defining factors \\
\hline K1 & it is the type of task to be performed \\
\hline K2 & $\begin{array}{l}\text { the time of the employee available to complete the } \\
\text { task }\end{array}$ \\
\hline K3 & $\begin{array}{l}\text { the level of experience and quality that the employee } \\
\text { has in performing his/her work }\end{array}$ \\
\hline K4 & the mental state of the employee's mind \\
\hline K5 & these are environmental and ergonomic conditions \\
\hline
\end{tabular}

Based on the figures given, the overall likelihood of human error can be calculated using the following formula (1). 
Table 4: TESEO method and its quantitative characterization of factors.

\begin{tabular}{|c|c|c|c|c|}
\hline Factor & Category & Qualitative characteristics & \multicolumn{2}{|c|}{ Ki value } \\
\hline \multirow[t]{3}{*}{ K1 } & \multirow[t]{3}{*}{ Factor of the type of task being performed } & Simple, routine task & & 0.001 \\
\hline & & A task that requires some attention & & 0.01 \\
\hline & & An unusual task with a high need for attention & & 0.1 \\
\hline \multirow[t]{8}{*}{ K2 } & \multirow[t]{3}{*}{ Transient stress factor in normal activity } & \multirow{7}{*}{ Standby time } & 2 & 10 \\
\hline & & & 10 & 1 \\
\hline & & & 20 & 0.5 \\
\hline & \multirow[t]{5}{*}{ Stress factor of extraordinary activity } & & 3 & 10 \\
\hline & & & 30 & 1 \\
\hline & & & 45 & 0.3 \\
\hline & & & 60 & 0.1 \\
\hline & & Professionally trained worker, expert & & 0.5 \\
\hline \multirow[t]{2}{*}{ K3 } & \multirow[t]{2}{*}{ Quality and experience factor } & Average knowledge and training of the worker & & 1 \\
\hline & & Poor to no expert knowledge & & 3 \\
\hline \multirow[t]{3}{*}{ K4 } & \multirow[t]{3}{*}{ Factor of mental state of mind } & Severe unforeseeable situation & & 3 \\
\hline & & Emergency & & 2 \\
\hline & & Normal usual condition & & 1 \\
\hline \multirow[t]{5}{*}{ K5 } & \multirow[t]{5}{*}{ Environmental and ergonomic factor } & $\begin{array}{l}\text { Excellent vibroacoustic environment and coordination with } \\
\text { the operating environment }\left(\mathrm{L}_{\mathrm{AEX}, 8 \mathrm{~h}}<75 \mathrm{~dB}\right)\end{array}$ & & 0.7 \\
\hline & & Good vibroacoustic environement $\left(\mathrm{L}_{\mathrm{AEX}, 8 \mathrm{~h}}=75 \mathrm{~dB}-80 \mathrm{~dB}\right)$ & & 1 \\
\hline & & Poor vibroacoustic environement $\left(\mathrm{L}_{\mathrm{AEx}, 8 \mathrm{~h}}=80 \mathrm{~dB}-85 \mathrm{~dB}\right)$ & & 3 \\
\hline & & $\begin{array}{l}\text { Intermittent vibroacoustic environment and poor coordinati- } \\
\text { on with the operating environment }\left(\mathrm{L}_{\mathrm{AEX}, \mathrm{gh}}=85 \mathrm{~dB}-87 \mathrm{~dB}\right)\end{array}$ & & 7 \\
\hline & & Incorrect vibroacoustic environment $\left(\mathrm{L}_{\mathrm{AEX}, 8 \mathrm{~h}}>87 \mathrm{~dB}\right)$ & & 10 \\
\hline
\end{tabular}

Table 5: Measured values at workplaces evaluated using the TESEO method.

\begin{tabular}{|c|c|c|c|c|c|c|}
\hline Workplaces and work activities & $\begin{array}{l}\text { Factor } \\
\text { K1 }\end{array}$ & $\begin{array}{l}\text { Factor } \\
\text { K2 }\end{array}$ & $\begin{array}{l}\text { Factor } \\
\text { K3 }\end{array}$ & $\begin{array}{l}\text { Factor } \\
K 4\end{array}$ & $\begin{array}{l}\text { Factor } \\
K 5\end{array}$ & $\begin{array}{l}\text { Probability of } \\
\text { failure }\end{array}$ \\
\hline \multicolumn{7}{|l|}{ Workplace 1} \\
\hline Attendance of welding robot & 0.01 & 10 & 0.5 & 1 & 10 & 0.5 \\
\hline \multicolumn{7}{|l|}{ Workplace 2} \\
\hline Welding & 0.01 & 1 & 0.5 & 1 & 1 & 0.005 \\
\hline Impurities grinding-off & 0.01 & 1 & 1 & 1 & 1 & 0.01 \\
\hline \multicolumn{7}{|l|}{ Workplace 3} \\
\hline Grinding of finished welds & 0.001 & 1 & 0.5 & 1 & 10 & 0.005 \\
\hline Simple surface treatment & 0.001 & 1 & 1 & 1 & 10 & 0.01 \\
\hline Material processign & 0.01 & 1 & 0.5 & 1 & 10 & 0.05 \\
\hline
\end{tabular}

\section{$P(H E P)=K 1 \times K 2 \times K 3 \times K 4 \times K 5$}

InTab. 4, there are specific numerical values of the individual factors Ki, based on which it is evaluated whether there is or there is not a likelihood of human error. Summing up all the numerical values of the five factors, we achieve the number greater than 1 , so there is a chance that the probability of human failure is high. [3]

The TESEO method estimates the reliability of the human factor using five factors that have been rated as the most important of all the factors influencing the probability of human error. Therefore, we consider this model to be the most suitable among all models for assessing the risks (human error) to a 
given production hall. Other possible models such as ETA and FTA are unreliable.

\section{Achievements}

In the welding operation, values were measured using a noise analyzer to analyse the reliability of the human factor and are shown in Tab. 5. The empirical method TESEO by G.C. Bello and C. Columbori was used to evaluate the measured values, by means of which the probability of human failure in performing the work activity of workers is revealed. The human factor assessment was carried out at the job description of the welding robot programmer, grinder and welder. The effects of noise on employees and other factors affect the workload and the likelihood of a human factor failing at work performance.

Using the TESEO method the measured values of noise load per human factor were evaluated. From the achieved coefficients from Tab. 5, it is evident that the work position at workstation 1 - robotic welding attended by the operator is the riskiest in terms of human factor failure.

\section{Conclusions}

Using the TESEO method, which clearly defined the quantities of noise burden on the human organism and thus carried out the analysis of individual workplaces from noise exposure, according to the results in Tab. 5, a clearly identified workplace that is the most risky and most likely to fail human factor due to high exposure to noise. The riskiest workplace is the workplace with the operation of the welding robot. And even though this work does not require a great deal of mental stress and concentration, but the noise caused by the machine, it has a negative impact on humans.

Human activity, concentrated in an open or enclosed space, is still considered to be the main cause of work-related accidents. It is therefore important to carry out evaluations, measurements and analyses of the impact of external factors that affect humans in order to prevent or reduce the risk of the occurrence of threats due to the reliability of the human factor.

\section{Acknowledgments}

The present article was prepared within the projects of grant agencies APVV-15-0351 "Development and Application of a Risk Management Model in the Setting of Technological Systems in
Compliance with Industry 4.0 Strategy" and VEGA 1/0121/18 "Development of methods of implementation and verification of complex security solution in Smart Factory as part of Industry 4.0 Strategy".

\section{References and Notes}

1. BALLUCH, R.: Analýza príčin vybraných závažných havárií zdvíhacích zariadení vo svete $v$ poslednom čase. Bezpečná práca,47 (3), str.6-11, 2016

2. BAUM , F.: Umweltschutz in der Praxis, 2.Auflage, R.Oldenburg Verlag München, Wien, 1998 , ISBN 3-48622632-0 15

3. P.A. a kol. Ergonomická rizika a pracovní podmínky operátorů $\vee$ rídicích centrech. In Bezpečnost a ochrana zdraví při práci 2015. Ostrava: SPBI, 2015. s87-92. ISBN 97880-7385-162-0

4. STN EN ISO 9612:2009, Akustika. Stanovenie expozície hluku v pracovnom prostredí. Technická metóda

5. How to avoid or reduce the exposure of workers to noise at work [online]. [S.I.] : European Commission, 2006 [cit. 11. 8. 2010].

6. South, T. Managing noise and vibration at work. Oxford : Elsevier ButterworthHeinemann, 2004. 278 s. ISBN 0-75066342-1.

7. Salvendy, G. Handbook of human factors and ergonomic. Hoboken : John Willey and Sons, 2005. S. 612-642. ISBN 13 978-471-44917-1.

8. Piňosová, M., Andrejiová, M., Badida, M. and Moravec, M.: Analysis and Evaluation of Risks from Exposure to Noise in a Working Environment, Acta Mech. Slovaca, vol. 22, no. 3, pp. 44-52, 2018. 